\title{
EKSISTENSI PENGELOLAAN TATA USAHA PADA LEMBAGA TINGGI SWASTA
}

\author{
Agus Fahmi \\ Program StudiAdministrasi Pendidikan, FIPP Undikma \\ Email:fahmieal2@gmail.com
}

\begin{abstract}
The academic management system at Tertiary Education Institutions is the core of the implementation of Higher Education activities that regulate all matters including the effectiveness of implementation, information, service quality, and efficient use of resources. Management strategy is a process or series of decision-making activities that are fundamental and comprehensive, accompanied by determining how to carry it out, which is made by the leadership and implemented by all levels in an organization to achieve goals. In the implementation of Private Higher Education (PTS) it is imperative that the quality of academic services be carried out in a directed, disciplined manner, with total quality, and ensures the realization of the quality of higher education properly. So far, many higher education institutions, especially private universities, have always put aside academic services, even only as a symbol for academic services within the institution. In fact, when viewed from various perspectives it is common knowledge that effective academic services will have a positive effect on the quality of the institution. Therefore it is very important to determine a strategy that supports the achievement of goals, because strategic is a large-scale planning (called strategic planning) that is oriented towards a far-reaching future (called a vision), and is determined as the decision of the highest leadership (decisions that are fundamental and principle), in order to enable the organization to interact effectively (called a mission), in an effort to produce something (operational planning to produce goods and / or services and services) of quality, directed at optimizing the achievement of goals (called strategic objectives) and various objectives (operational objectives). ) organization (Nawawi, 2003).
\end{abstract}

\section{Keywords: Existence Management, Private College}

Abstrak: Sistem manajemen akademik pada Perguruan Tinggi merupakan inti dari pelaksanaan kegiatan Pendidikan Tinggi yang mengatur tentang segala hal yang mencakup efektifitas penyelenggaraan, informasi, kualitas layanan, serta pemanfaatan sumber daya secara efisien. Strategi manajemen merupakan proses atau rangkaian kegiatan pengambilan keputusan yang bersifat mendasar dan menyeluruh, disertai penetapan cara melaksanakannya, yang dibuat oleh pimpinan dan diimplementasikan oleh seluruh jajaran di dalam suatu organisasi untuk mencapai tujuan. Pada penyelenggaraan Pendidikan Tinggi Swasta (PTS) sudah menjadi keharusan bahwa kualitas layanan akademik dilaksanakan secara terarah, disiplin, totalquality, serta menjamin terwujudnya mutu pendidikan tinggi dengan baik. Selama ini banyak pendidikan tinggi khususnya PTS yang selalu mengesampingkan pelayanan akademik, bahkan hanya sebagai simbol agar adanya pelayanan akademik di dalam lembaga. Padahal, jika dilihat dari berbagai macam perspektif dan telah menjadi rahasia umum bahwa pelayanan akademik yang efektif akan berpengaruh positif terhadap mutu lembaga. Oleh karena itu sangat penting untuk menentukan suatu strategi yang menunjang tercapainya tujuan, karena strategis merupakan perencanaan berskala besar (disebut perencanaan strategi) yang berorientasi pada jangkauan masa depan yang jauh (disebut visi), dan ditetapkan sebagai keputusan pimpinan tertinggi (keputusan yang bersifat mendasar dan prinsipil), agarmemungkinkan organisasi berinteraksi secara efektif (disebut misi), dalam usaha menghasilkan sesuatu (perencanaan operaional untuk menghasilkan barang dan/atau jasa serta pelayanan) yang berkualitas, dengan diarahkan pada optimalisasi pencapaian tujuan (disebut tujuan strategis) dan berbagai sasaran (tujuan operasional) organisasi (Nawawi, 2003).

Kata Kunci: Eksistensi Pengelolaan, PTS

\section{LATAR BELAKANG}

Sistem informasi, sistem nilai, dan sistem pelayanan akademik yang efektif dan berkualitas menjadi tonggak utama dalam penyelenggaraan perguruan tinggi. Perguruan tinggi adalah lembaga pendidikan yang tertinggi dalam sistem pendidikan nasional di semua negara. Perguruan tinggi harus bisa mengantarkan peserta didiknya memahami dirinya sendiri, menentukan peran dirinya dalam masyarakat dan menjadikannya sebagai manusia yang jauh lebih baik dari yang sebelumnya. Perguruan tinggi bukanlah perusahaan yang senantiasa hanya mengejar keuntungan financial, bukan badan amal, 
melainkan sebuah industri paling vital yang harus dikelola secara efektif dan efisien. Globalisasi telah mendorong timbulnya persaingan yang sangat kompetitif dalam dunia jasa pendidikan. Perguruan tinggi saling berlomba untuk mengembangkan seluruh potensi dan kemampuannya guna menarik minat calon mahasiswa. Kemampuan bersaing tersebut sangat dipengaruhi oleh kinerja manajemen perguruan tinggi yang bersangkutan dalam merencanakan strategi yang berorientasi dalam rangka membangun daya saing yang tinggi.

Marshall \& Jhonston (2010 ; 13) mengemukan dalam pemasaran jasa konsep bauran pemasaran tradisional yang terdiri dari $4 \mathrm{P}$ kurang memadai, perlu diperluas dengan menambahkan beberapa konsep yaitu people, physicalevidence dan process, sehingga menjadi tujuh unsur (7 P). Penambahan unsur bauran pemasaran jasa dilakukan karena jasa memiliki karakteristik yang berbeda dengan produk yaitu: tidak berwujud (intangibility), tidak terpisahkan (inseparability), bervariasi (variability), dan tidak tahan lama (perishability). Lebih lanjut Loan (2011) melakukan penelitian bertujuan untuk mengembangkan penggunaan 7 kerangka $P$ dibidang pemasaran pendidikan. Dengan menghadirkan beberapa hal penting kerangka informasi dalam pasar pendidikan sehingga konteks yang diteliti terbukti. Kemudian $\begin{array}{lllll}\text { kerangka } & 7 & \mathrm{P} & \text { digunakan untuk }\end{array}$ mengumpulkan informasi satu per-satu produk. Kerangka $7 \mathrm{P}$ itu adalah product (produk), Price (harga), placement (tempat), promotion (promosi), people (orang), process (proses) dan physicalevidence (bukti fisik). Dalam penelitian ini menunjukkan bahwa masing-masing memiliki sinergi peran tertentu ketika datang ke pasar pendidikan.
Masalah yang selalu muncul tersebut berdampak pada adanya kesenjangan antara jumlah pendaftar/calon peminat dan jumlah yang diharapkan dapat diterima di perguruan tinggi swasta (PTS). Hal ini merupakan dampak dari strategi bersaing, strategi pemasaran yang dipakai, kualifikasi SDM atau pergeseran aspirasi para calon mahasiswa dan faktor faktor lain yang berperan dalam mempersepsi dan mendeterminasi keputusan para calon mahasiswa untuk melanjutkan studi di perguruan tinggi tersebut.

\section{KAJIAN PUSTAKA}

\section{Definisi Umum Strategi Manajemen}

Manajemen strategik adalah seni dan pengetahuan dalam merumuskan, mengimplementasikan, serta mengevaluasi keputusan-keputusan lintas fungsional yang memungkinkan sebuah organisasi untuk mencapai tujuan (David, 2011:6). Manajemen strategis berfokus pada proses penetapan tujuan organisasi, pengembangan kebijakan dan perencanaan untuk mencapai sasaran, serta mengalokasikan sumber daya untuk menerapkan kebijakan dan merencanakan pencapaian tujuan organisasi. Manajemen strategis mengkombinasikan aktivitas-aktivitas dari berbagai bagian fungsional suatu bisnis untuk mencapai tujuan organisasi.

Beberapa ahli berpendapat bahwa:

a. Thomas Wheelen dkk (2010:105), Manajemen strategi adalah serangkaian dari pada keputusan manajerial dan kegiatan-kegiatan yang menentukan keberhasilan perusahaan dalam jangka panjang. Kegiatan tersebut terdiri dari perumusan/perencanaan strategi, 
pelaksanaan/implementasi dan evaluasi.

b. Bambang Haryadi (2003:3), strategi manajemen adalah suatu proses yang dirancang secara sistematis oleh manajemen untuk merumuskan strategi, menjalankan strategi dan mengevaluasi strategi dalam rangka menyediakan nilainilai yang terbaik bagi seluruh pelanggan untuk mewujudkan visi organisasi.

c. Mulyadi (2001:40), Manajemen strategi adalah suatu proses yang digunakan oleh manajer dan karyawan untuk merumuskan dan mengimplementasikan strategi dalam penyediaan costumer value terbaik untuk mewujudkan visi organisasi.

Jadi, Manajemen strategik merupakan proses penetapan tujuan, perumusan kebijakan, dan perencanaan pendidikan secara sistematis dalam mewujudkan visi organisasi secara efektif dan efisien.

\section{Model Manajemen Strategik}

Manajemen strategik berawal dari mengidentifikasi visi organisasi yang sudah ada, misi, tujuan, dan strategi adalah titik awal yang logis untuk manajemen strategis karena situasi sekarang perusahaan dan kondisi dapat menghalangi strategi tertentu dan bahkan mungkin mendikte tindakan tertentu. Setiap organisasi memiliki visi, misi, tujuan, dan strategi,bahkan jika unsur-unsur ini tidak sadar dirancang, ditulis, atau dikomunikasikan. Manajemen strategik memiliki tahapan atau proses yang disusun dan terstruktur dalam bentuk model seperti gambar di bawah ini:

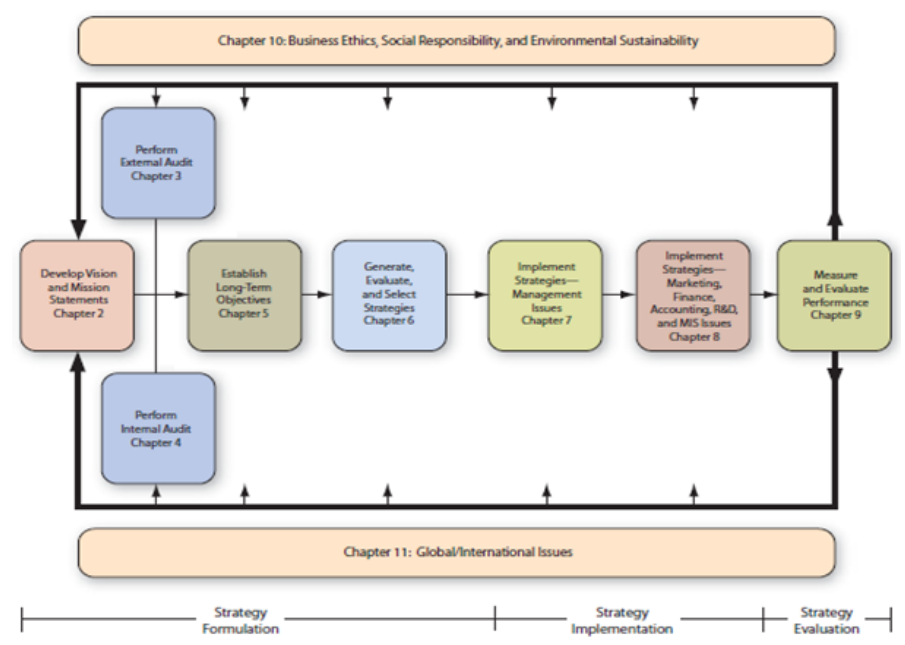

Gambar 2.1 Model Proses Manajemen Strategik (David, 2011:15)

2. Proses dan Tahapan Manajemen Strategi
David (2011:6) menjelaskan bahwa proses manajemen strategis terdiri dari tiga tahapan, yaitu : 
a. PerumusanStrategi

(Strategy

\section{Formulation)}

Perumusan strategi adalah tahap awal pada manajemen strategi, yang mencakup mengembangkan visi dan misi, mengidentifikasi peluang eksternal organisasi dan ancaman, menentukan kekuatan dan kelemahan internal, menetapkan tujuan jangka panjang, menghasilkan strategi alternatif, dan memilih strategi tertentu untuk mencapai tujuan.

b. Implementasi Strategi (Strategy Implemented)

Implementasi strategi adalah tahap selanjutnya sesudah perumusan strategi yang ditetapkan. Penerapan strategi ini memerlukan suatu keputusan dari pihak yang berwenang dalam mengambil keputusan untuk menetapkan tujuan tahunan, menyusun kebijakan, memotivasi karyawan, dan mengalokasikan sumber daya sehingga strategi yang dirumuskan dapat dilaksanakan. Pada tahap ini dilakukan pengembangan strategi pendukung budaya, merencanakan struktur organisasi yang efektif, mengatur ulang usaha pemasaran yang dilakukan, mempersiapkan budget, mengembangkan dan utilisasi sistem informasi serta menghubungkan kompensasi karyawan terhadap kinerja organisasi.

\section{c. Evaluasi Strategi (Strategy Evaluation)}

Evaluasi strategi adalah tahap akhir dalam manajemen strategis. Manajer sangat membutuhkan untuk tahu kapan strategi tertentu tidak bekerja dengan baik; Evaluasi strategi adalah alat utama untuk memperoleh informasi ini. Hal tersebut dapat dilakukan dengan penilaian atau melakukan proses evaluasi strategi. Dalam penilaian strategi terdapat tiga aktivitas penilaian yang mendasar, yaitu: Peninjauan ulang faktor-faktor eksternal dan internal yang menjadi landasan bagi strategi saat ini, Pengukuran kinerja, dan 3). Pengambilan langkah korektif. Penilaian strategi sangat diperlukan oleh suatu perusahaan karena strategi yang berhasil untuk saat ini tidak selalu berhasil untuk di masa yang akan datang.

\section{Pendidikan Tinggi Swasta (PTS)}

Menurut kamus Webster's Now World Dictionary (1962), pendidikan adalah proses pengembangan dan latihan yang mencakup aspek pengetahuan (knowledge), keterampilan (skill) dan kepribadian (character), terutama dilakukan dalam suatubentuk formula kegiatan pendidikan mencakup proses dalam menghasilkan dan transfer ilmu pengetahuan yang dilakukan oleh individu atau organisasi belajar (dalam Nanang Fatah, 2004: 14).

Fungsi pendidikan adalah menyiapkan manusia muda yang berkualitas, menyiapkan tenaga kerja dan menyiapkan warga negara yang baik (Dwi Siswoyo, dkk. 2007: 83).Tujuan pendidikan nasional berdasarkan UndangUndang No 20 Tahun 2003 pasal 3 adalah, "Untuk berkembangnya potensi peserta didik agar menjadi manusia yang beriman 
dan bertakwa kepada Tuhan Yang Maha Esa, berakhlak mulia, sehat, berilmu, cakap, kreatif, mandiri dan menjadi warga negara yang demokratis serta bertanggungjawab".Berdasarkan pengertian, fungsi dan tujuan pendidikan diatas, pendidikan dapat diartikan sebagai proses penyiapan manusia untuk berkembang dan berlatih menjadi manusia berkualitas yang memiliki pengetahuan, keterampilan dan kepribadian untuk menjadi manusia yang beriman dan bertakwa kepada Tuhan Yang Maha Esa, berakhlak mulia, sehat, berpengetahuan, berketerampilan, cakap, kreatif, mandiri, dan bertanggungjawab untuk menjadi tenaga kerja dan warga yang baik.

Pendidikan tinggi merupakan tumpuan akhir seluruh jenjang pendidikan dan sebagai wahana pembentukan sarjana yang memiliki budi pekerti luhur, melangsungkan nilai-nilai kebudayaan, memajukan kehidupan dan membentuk satria pinandita (Harsono, 2008: 22). Pasal 34 ayat 2 Peraturan Pemerintah No 2 Tahun 1990, menjelaskan bahwa tujuan pendidikan tinggi adalah sebagai berikut:a.Menyiapkan peserta didik menjadi anggota masyarakat yang memiliki kemampuan akademik dan atau profesionalyang dapat menerapkan, mengembangkan atau menciptakan ilmu pengetahuan, teknologi dan atau kesenian.b.Mengembangkan dan menyebarluaskan ilmu pengetahuan, teknologi dan atau kesenian serta mengupayakan penggunaannyauntuk meningkatkantaraf kehidupan masyarakat dan memperkaya kebudayaan nasional (dalam Sudiyono, 2004: 2).

Perguruan tinggi memiliki tiga fungsi utama, yaitu: a. Pengembangan sumber daya manusia (human resource development)b.Pengembangan sains dan teknologic. Sebagai agen perubahan sosial (Mohammad Ali, 2009: 177). Menurut Sudiyono (2004: 23), bahwasanya pendidikan tinggi terdiri dari pendidikan akademik dan profesional. Sementara pendidikan tinggi dapat berbentuk akademik dan politeknik, sekolah tinggi institut dan universitas.

\section{METODE PENELITIAN}

Penelitian ini berupaya mengungkap Strategi Manajemen akademik pada pendidikan tinggi swasta. Metode penelitian yang digunakan pada penelitian ini adalah metode penelitian kualitatif yaitu pendekatan yang temuan-temuan penelitiannya tidak diperoleh melalui prosedur statistik atau bentuk perhitungan lainnya, prosedur ini menghasilkan temuan-temuan yang diperoleh dari data-data yang dikumpulkan dengan menggunakan beragam sarana meliputipengamatan dan wawancara, namun bisa juga mencakup dokumen, buku, kasetvideo, dan bahkan data yang telah dihitung untuk tujuan lain, misalnya data sensus.

Dalam penelitian kualitatif langkahlangkah/tahap-tahapan itu secara garis besar dibagi kedalam tiga bagian, yaitu; 1) Tahapan persiapan/pra-lapangan, 2) Tahapan pekerjaan lapangan, dan 3) Tahapan analisis data. Adapun rincian tahapan-tahapan tersebut adalah sebagai beriku:

1) Pra-Lapangan
a. Menyusun rancangan
b. Memilih lapangan
c. Mengurus perijinan
d. Menjajagi dan menilai keadaan
e. Memilih dan memanfaatkan informan 
f. Menyiapkan instrumen

g. Persoalan etika dalam lapangan

2) Lapangan

a. Memahami dan memasuki lapangan

b. Pengumpulan data

3) Pengolahan Data

a. Reduksi data

b. Display data

c. Analisis

\section{HASIL PENELITIAN}

Manajemen Akademik Pada FIPP Undikma

Sebagaimana telah dibahas pada penjelasan sebelumnya bahwa Manajemen Akademik merupakan implementasi dari fungsi manajemen pendidikan yakni Perencanaan, Pengorganinsasian, Penggerakkan, pengawasan, dan evaluasi dalam rangka memberikan pelayanan akademik kepada civitas akademika Undikma khususnya pada tingkat Fakultas FIPP dan masyarakat pendidikan pada umumnya. Tradisi yang dibangun adalah memberikan pelayanan terbaik dengan konsep Total Quality Management (TQM). Total Management System atau disingkat dengan TQM adalah suatu sistem manajemen kualitas yang berfokus pada Pelanggan (Customer focused) dengan melibatkan semua level karyawan dalam melakukan peningkatan atau perbaikan yang berkesinambungan (secara terus-menerus). TQM menggunakan strategi, data dan komunikasi yang efektif untuk mengintegrasikan kedisplinan kualitas ke dalam budaya dan kegiatan-kegiatan akademik. Singkatnya, Total Quality Management (TQM) adalah pendekatan manajemen untuk mencapai keberhasilan jangka panjang melalui Kepuasan Pelanggan (Customer Satisfaction).

Pada konsep yang demikian dikemukakan juga oleh Crosby yang terkenal dengan anjuran manajemen zero defect dan pencegahan yang menentang tingkat kualitas yang dapat diterima secara statistik "acceptable quality level”, pandangan-pandangan Crosby dirangkumnya dalam ringkasan yang ia sebut sebagai dalil-dalil manajemen kualitas yaitu:

a. Definisi kualitas adalah sama dengan persyaratan

b. Sistem kualitas adalah pencegahan

c. Kerusakan nol "zero effect" merupakan standar kinerja yang harus digunakan

d. Ukuran kualitas adalah price of nonconformance

Pandangan lain tentang manfaat TQM yakni dari Hessel digambarkan sebagai berikut:

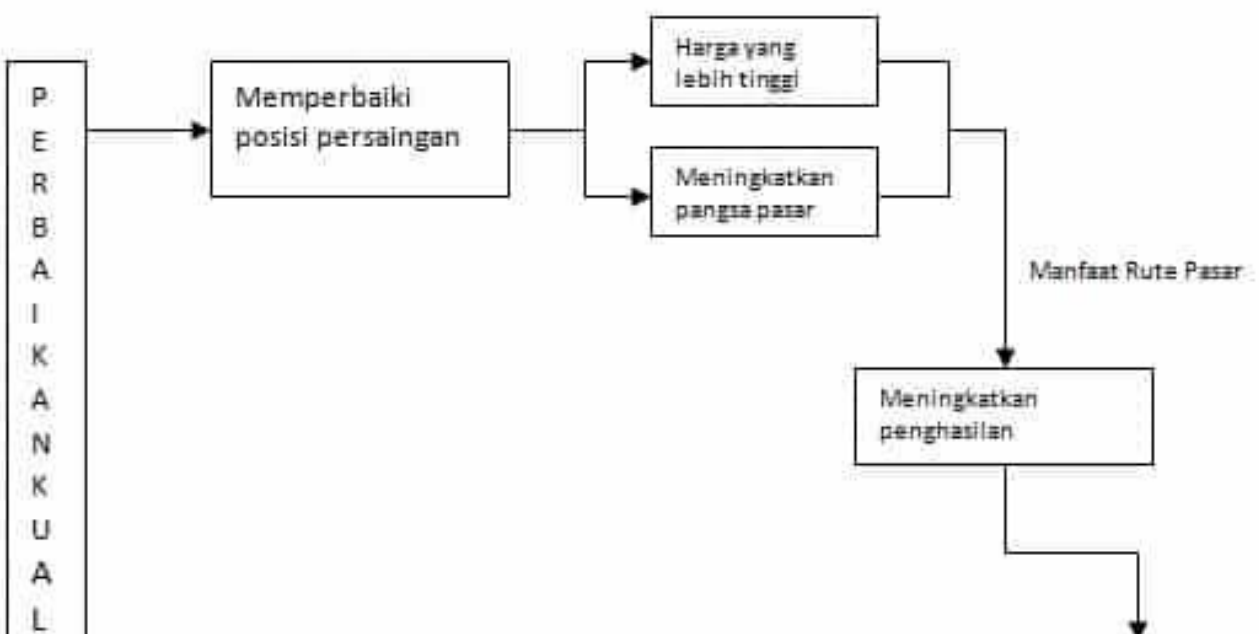


Menurut Hessel, manfaat penerapan Total Quality Manajemen ( TQM ) bagi perusahaan/organisasi adalah (Nasution, 2005: 366)

a. Proses desain produk menjadi lebih efektif yang akan berpengaruh pada kinerja kualitas yaitu keandalan produk, product features dan serviceability.

b. Penyimpangan yang dapat dihindari pada proses produksi mengakibatkan produk yang dihasilkan sesuai dengan standar, menjadikan pengerjaan ulang, mengurangi waktu kerja, mengurangi kerja mesin dan menghemat penggunaan material.

c. Hubungan jangka panjang dnegan pelanggan akan berpengarug positif bagi kinerja organisasi, antara lain dapat merespon kebutuhan pelanggan dengan lebih cepat serta mengantisipasi perubahan kebutuhan dan keinginan pelanggan.

d. Sikap pekerja yang baik akan menimbulkan partisipasi dan komitmen pekerja pada kualitas, rasa bangga bekerja sehingga akan bekerja secara optimal, perasaan tanggung jawab untuk meningkatkan kinerja organisasi.

\section{PEMBAHASAN}

Perencanaan pada kegiatan akademik Fakultas Ilmu Pendidikan dan Psikolgi Undikma, dimulai dengan menggunakan pola bottom-up yang diwujudkan dalam bentuk kegiatan menyusun rencana strategis dan rencana kerja yang selanjutnya kegiatan dituangkan menjadi program kerja tahunan untuk dilaksanakan selama setahun pada tahun berikutnya. Kegiatan penyusunan perencanaan atas program- program kampus untuk satu tahun dan untuk tahun berikutnya dilakukan tidak sekaligus, dan serta melibatkan semua yang bertanggungjawab terhadap akademik. Perencanaan akademik itu memiliki prinsip- prinsip perencanaan supaya perencanaan tersebut tercapai target. Hal ini sesuai apa yang telah dikemukakan oleh Usman (2013: 152) "Agar perencanaan menghasilkan rencana yang baik, konsisten, dan realistis, maka kegiatan-kegiatan perencanaan perlu memperhatikan beberapa prinsip perencanaan yang baik adalah sebagai berikut:

(1) keadaan sekarang tidak dimulai dari nol, tetapi dari sumber daya yang sudah ada; (2) keberhasilan dan faktor-faktor kritis keberhasilan; (3) kegagalan masa lampau; (4) potensi, tantangan, dan kendala yang ada; (5) kemampuan merubah kelemahan menjadi kekuatan, dan ancaman menjadi peluang analisis (strengths, weaknesses, opportunities, 
and threats atau SWOT);

(6)

Mengikutsertakan pihak-pihak terkait; (7) memperhatikan komitmen dan mengkoordinasikan pihak-pihak terkait; (8) mempertimbangkan efektivitas dan efisiensi, demokratis, transparan, realistis, legalistis, dan praktis; (9) jika mungkin, mengujicobakan kelayakan perencanaan.

Keberadaan perencanaan dalam suatu organisasi termasuk perguruan tinggi sangat penting, karena melalui perencanaan akan dapat ditentukan tujuan, kebijakan, prosedur program serta dapat memberikan pedoman pelaksanaan kerja yang efektif dalam mencapai tujuan organisasi, dan perencanaan yang baik akan melahirkan tindakan ekonomis dan menghindari dari pemborosan pemanfaatan sumber daya organisasi. Engkoswara dan Komariah (2011:94) mengemukakan bahwa keberadaan suatu rencana sangat penting bagi suatu organisasi, karena rencana berfungsi untuk: a. Menjelaskan dan merinci tujuan yang ingin dicapai; b. Memberikan pegangan dan menetapkan kegiatan-kegiatan yang harus dilakukan untuk mencapai tujuan tersebut; c. Organisasi memperoleh standar sumber daya terbaik dan mendayagunakan sesuai tugas pokok fungsi yang telah ditetapkan; $d$. Menjadi rujukan anggota organisasi dalam melaksanakan aktivitas yang konsisten prosedur dan tujuan; e. Memberikan batas kewenangan dan tanggung jawab bagi seluruh pelaksana; f. Memonitor dan mengukur berbagai keberhasilan secara intensif sehingga bias menemukan dan memperbaiki penyimpanan secara dini; g. Memungkinkan untuk terpeliharanya persesuaian antara kegiatan internal dengan situasi eksternal; h. Menghindari pemborosan.

\section{KESIMPULAN}

Pada penyelenggaraan Pendidikan Tinggi Swasta (PTS) sudah menjadi keharusan bahwa kualitas layanan akademik dilaksanakan secara terarah, disiplin, totalquality, serta menjamin terwujudnya mutu pendidikan tinggi dengan baik. Selama ini banyak pendidikan tinggi khususnya PTS yang selalu mengesampingkan pelayanan akademik, bahkan hanya sebagai simbol agar adanya pelayanan akademik di dalam lembaga. Padahal, jika dilihat dari berbagai macam perspektif dan telah menjadi rahasia umum bahwa pelayanan akademik yang efektif akan berpengaruh positif terhadap mutu lembaga. Oleh karena itu sangat penting untuk menentukan suatu strategi yang menunjang tercapainya tujuan, karena strategis merupakan perencanaan berskala besar (disebut perencanaan strategi) yang berorientasi pada jangkauan masa depan yang jauh (disebut visi), dan ditetapkan sebagai keputusan pimpinan tertinggi (keputusan yang bersifat mendasar dan prinsipil), agarmemungkinkan organisasi berinteraksi secara efektif (disebut misi), dalam usaha menghasilkan sesuatu (perencanaan operaional untuk menghasilkan barang dan/atau jasa serta pelayanan) yang berkualitas, dengan diarahkan pada optimalisasi pencapaian tujuan (disebut tujuan strategis) dan berbagai sasaran

\section{DAFTAR PUSTAKA}

Baharuddin. 2010. Pendidikan dan Psikologi perkembangan. Jogjakarta: Ar-Ruzz Media.

Bogdan, Robert C, and Biklen S.K., (1982). Qualitative Research in Education, Boston, Allyn \& Bacon, inc. 
David, Fred R. 2011. Strategic Management Manajemen Strategi Konsep, Edisi 12. Jakarta: Salemba Empat.

Dwi Siswoyo, $2007 . \quad$ Ilmu Pendidikan. Yogyakarta: UNY Pers.

Echols, John M. and Shadily, Hassan. 2015. Kamus Inggris-Indonesia, cet.XXVI. Jakarta, PT Gramedia Pustaka.

Engkoswara, dkk. 2010. Administrasi Pendidikan. Bandung: Alfabeta.

Fattah, Nanang, 2008. Landasan Manajemen Pendidikan. Bandung: Remaja Rosdakarya.

Fidler, B. 2012. Strategic Management for School Development. London: Paul Chapman Publishing.

Glueck, Wiliam F. 2011. Manajemen Strategis dan kebijakan Perusahaan. Erlangga: Jakarta.

H. Gunawan Ary, 2011. Administrasi Pendidikan Mikro. Jakarta : Rineka Cipta.

Hariadi, Bambang. 2013. Strategi Manajemen. Malang: Banyumedia Publishing.

Lincoln, Yvonna S. \& Guba, Egon G. (1985). Naturalistic Inquiry. California, Beverly Hills: Sage Publications.

Miles, M.B. \& Huberman, A.M. 1992. Analisis Data Kualitatif. Terjemahan oleh Tjetjep Rohendi Rohidi. Jakarta : UI-Press.

Mulyadi. 2011. Akuntansi Manajemen : Konsep, Manfaat dan Rekayasa, Edisi Ketiga. Jakarta: Salemba Empat.
Nawawi, 2003. Manajamen Sumber Daya Manusia untuk Bisnis yang Kompetitif. Gajah Mada University press: Yogyakarta.

Peraturan Menteri Pendidikan dan Kebudayaan. 2014. Standar Nasional PendidikanTinggi. Jakarta: Kementerian Pendidikan dan Kebudayaan.

Peraturan Menteri Pendidikan dan KebudayaanRI. No. 155/U/1998 Tentang Pedoman Umum OrganisasiKemahasiswaan di Perguruan Tinggi. Jakarta: Kementerian Pendidikan dan Kebudayaan.

Peraturan Menteri Riset, Teknologi, dan Pendidikan Nomor 50 Tahun 2015. Tentang Pendirian, Perubahan, dan Pembubaran Perguruan Tinggi. Jakarta: Kementerian Riset, Teknologi, dan Pendidikan Tinggi.Peraturan PemerintahNomor 30 Tahun 1990 Tentang Pendidikan Tinggi.Jakarta: Departemen Pendidikan dan Kebudayaan.Peraturan PemerintahNomor

4Tahun2014Tentang Penyelenggaraan Pendidikan Tinggi dan Pengelolaan PerguruanTinggi. Jakarta: Departemen Pendidikan dan Kebudayaan.

Seli, Muhammad, 2009. Metode pembelajaran pendidikan agama islam dalam full day school di sekolah alam bilingual Madrasah tsanawiyah surya buana Lowokwaru malang. Skripsi. Fakultas Tarbiyah Universitas Islam Negeri Malang.

Suwandiyanto, M. 2010. Manajemen Strategi dan Kebijakan Perusahaan. Online. 
Wheelen, Thomas L., Hunger, J. David. 2010. Strategic Management and Business Policy Achieving
Sustainability. Twelfth Edition. Pearson. 